\title{
INFLUÊNCIA DA TEMPERATURA NO DESENVOLVIMENTO DE Rhopalosiphum maidis (Fitch, 1856) (Hemiptera: Aphididae) EM CONDIÇÕES DE LABORATÓRIO
}

\author{
Influence of temperature on the development of Rhopalosiphum maidis \\ (Fitch, 1856) (Hemiptera: Aphidae) under laboratory conditions
}

\author{
Wilson J. Mello e Silva Maia ${ }^{1}$, César Freire Carvalho ${ }^{2}$, \\ Ivan $\mathrm{Cruz}^{3}$, Brígida Souza ${ }^{2}$, Terezinha J. A. Ferreira Maia $^{4}$
}

\begin{abstract}
RESUMO
O pulgão Rhopalosiphum maidis (Fitch) tem sido encontrado em todos os estádios de desenvolvimento do milho e na maioria dos municípios do Estado de Minas Gerais, e sua importância tem aumentado principalmente nas áreas onde se cultiva o milho "safrinha". Por isso, objetivou-se estudar a influência da temperatura sobre alguns aspectos biológicos das fases de ninfa e adulta desse afídeo em diferentes temperaturas em condições de laboratório. Os ensaios foram conduzidos em câmaras climatizadas reguladas a $15,18,21,24,27$ e $30 \pm 1^{\circ} \mathrm{C}$, UR de $70 \pm 10 \%$ e fotofase de 12 horas, no Laboratório de Biologia de Insetos do Departamento de Entomologia da Universidade Federal de Lavras - UFLA, MG, em delineamento inteiramente casualizado com cinco repetições com oito espécimens cada uma. Verificou-se uma correlação positiva entre todas as fases de desenvolvimento e a fecundidade de $R$. maidis com a temperatura, com exceção de 24 a $27^{\circ} \mathrm{C}$, em que ocorreu uma redução na fecundidade, observando-se uma relação ciclo biológico/fecundidade maior na temperatura $24^{\circ} \mathrm{C}$. Observou-se que a duração da fase de ninfa foi de 13,$3 ; 10,7 ; 6,7 ; 4,5 ; 4,7$ e 4,5 dias a $15,18,21,24,27$ e $30^{\circ} \mathrm{C}$, respectivamente, constatando-se um decréscimo linear em todos os ínstares, em razão do aumento da temperatura na faixa de 15 a $24^{\circ} \mathrm{C}$. Acima dessa temperatura, houve uma tendência de estabilização da velocidade de desenvolvimento. O período reprodutivo foi de 28 dias a 15 e $18^{\circ} \mathrm{C}$, estabilizando-se entre 21 e $27^{\circ} \mathrm{C}$, com uma duração próxima a 12 dias, ao passo que a $30^{\circ} \mathrm{C}$ houve uma redução para cinco dias. $\mathrm{O}$ ciclo biológico a $15^{\circ} \mathrm{C}$ foi de 52 dias, decrescendo em cerca de seis dias com a elevação para $18^{\circ} \mathrm{C}$. A maior redução foi observada entre 18 e $21^{\circ} \mathrm{C}$, registrando-se um decréscimo de 18 dias.
\end{abstract}

Termos para indexação: Pulgão-da-folha-do-milho, temperatura, biologia.

\section{ABSTRACT}

The aphid Rhopalosiphum maidis (Fitch) has been found in all the development stages of corn and in most towns of Minas Gerais state, Brazil, and its importance has increased mainly in areas where the "fall" corn is grown. Therefore, it was aimed to investigate the influence of temperature upon some biological features of the nymphal and adult stage at different temperatures under laboratory conditions. The trials were conducted in climatized chamber at $15,18,21,24,27$ and $30 \pm 1^{\circ} \mathrm{C}$, $\mathrm{RH}$ of $70 \pm 10 \%$ and 12-hour photophase in the Insect Biology Laboratory of the Entomology Department of the Universidade Federal de Lavras - UFLA, MG, Brazil, in a completely randomized design with five replicates with eight specimens each. A positive correlation among all the developmental stages and the fecundity of $R$. maidis with temperature was found, except between 24 to $27^{\circ} \mathrm{C}$, where a reduction in fecundity occured, noticing a higher relationship biologic cycle/fecundity at the temperature of $24^{\circ} \mathrm{C}$. It was observed that the duration of the nymphal stage was of $13.3,10.7,6.7,4.5,4.7$ and 4.5 days to 15,18 , $21,24,27$ and $30^{\circ} \mathrm{C}$, respectively, finding a linear decrease in all instars in terms of the increase of temperature in the range of 15 to $24^{\circ} \mathrm{C}$. Above that temperature there was a trend of stabilizing the development velocity. The reproductive period was of 28 days at 15 and $18^{\circ} \mathrm{C}$, became stable between 21 and $27^{\circ} \mathrm{C}$ with a duration close to 12 days whereas at $30^{\circ} \mathrm{C}$, there was a reduction to five days. The biological cycle at $15^{\circ} \mathrm{C}$ was of 52 days, decreasing about six days with the increase to $18^{\circ} \mathrm{C}$. The greatest reduction was found between 18 and $21^{\circ} \mathrm{C}$, recording a 18 -day decrease.

Index terms: Corn leaf aphid, temperature, biology.

(Recebido para publicação em 18 de fevereiro de 2003 e aprovado em 22 de abril de 2003)

\footnotetext{
1. Engenheiro Agrônomo, MSc., Dr., Departamento de Entomologia da Universidade Federal de Lavras/ UFLA - Caixa Postal 37 - $37200-000$ - Lavras, MG.

2. Professores do Departamento de Entomologia da UFLA.

3. Pesquisador EMBRAPA/CNPMS, Caixa Postal 151 - 35701-970 - Sete Lagoas, MG

4. Técnico em Laboratório, Funcionária da Universidade Federal Rural da Amazônia/UFRA.
} 


\section{INTRODUÇÃO}

A cultura do milho, uma das mais importantes no Brasil e no mundo, anualmente sofre queda na produção em razão, principalmente, dos danos causados por pragas e doenças (CRUZ, 2000a,b,c). A época de plantio, com a semeadura extemporânea, prolonga a oferta de alimento para as pragas e, aliada às condições ambientais, como temperatura e umidade relativa do ar e os tratamentos fitossanitários constantes (GASSEN e GASSEN, 1996), podem se transformar em fatores de aumento populacional de insetos-praga, bem como favorecer o surgimento de novos insetos nocivos ou mesmo mudar o "status" de uma praga secundária para primária (DUARTE, 2001).

Segundo Gassen (1996), Waquil et al. (1996) e Cruz (2000a), dentro da ampla e variada entomofauna associada ao milho, atualmente pode-se citar como insetos-praga importantes os vetores de Molicutes e viroses como a cigarrinha-do-milho, Dalbulus maidis (DeLong e Wolcott, 1923) (Hemiptera: Cicadellidae) e o pulgãoda-folha-do-milho, Rhopalosiphum maidis (Fitch, 1856) (Hemiptera: Aphididae). Esse afídeo era considerado como praga secundária na cultura mas, com o incremento do cultivo do milho "safrinha" na última década, os danos causados por esse inseto aumentaram em importância, observando-se problemas maiores em cultivares de milho-doce, em consequiência da transmissão do vírus-do-mosaico-anão. Portanto, os maiores danos são indiretos por se constituírem em um vetor de viroses e sua presença tem sido constatada praticamente em todo o Estado de Minas Gerais e em todos os estádios fenológicos do milho (PEÑA-MARTÍNEZ, 1992; GASSEN, 1996; WAQUIL et al., 1996).

A sucção incessante da seiva pelo afídeo depaupera a planta, levando-a, em infestações maciças, ao definhamento geral. As folhas ficam cloróticas, encarquilhadas e enroladas, com manchas marrom-amareladas, recobertas de "honeydew" (OS PULGÕES..., 1967). Segundo Gassen (1996) e Martins e Ferrão (1990), a infestação por esse afídeo inicia-se em plantas isoladas, disseminando-se em manchas na lavoura, com sua presença sendo constatada no período vegetativo e, principalmente, próximo ao lançamento do pendão. Nessa fase, as folhas encontram-se enroladas, formando cartucho de proteção, onde os insetos sugam a seiva continuamente e multiplicam-se com facilidade, mas sem importância econômica direta. Todavia, altas infestações no período de pré-florescimento pode ocasionar perda econômica, principalmente se a planta estiver com estresse hídrico e nos estádios correspondentes à iniciação floral e desenvolvimento da inflorescência, período de fertilização e enchimento de grãos (EVERLY, 1960; BRODBECK e STRONG, 1987; HONĚK 1990, 1991; MAGALHÃES et al., 1995).

Apesar de se conhecer desde meados do século XVIII, que o crescimento e o desenvolvimento dos insetos dependem da temperatura, pelo fato de esses organismos serem poiquilotérmicos, esse conceito ainda é útil na agricultura moderna (CIVIDANES, 2000), podendo-se utilizar as exigências térmicas dos insetos na previsão de picos populacionais e épocas de amostragem, controle biológico, tabelas de vida, zoneamento ecológico e modelos para o manejo de insetos-praga. Segundo Silveira Neto et al. (1976), entre 15 e $38^{\circ} \mathrm{C}$, encontra-se a faixa ótima de desenvolvimento e atividade da maioria dos insetos, e, o preferendo de temperatura é estabelecido pelo intervalo que agrupa $75 \%$ dos indivíduos.

Por se tratar de uma praga emergente na cultura do milho, objetivou-se estudar a influência da temperatura sobre alguns aspectos biológicos das fases de ninfa e adulta de $R$. maidis.

\section{MATERIAL E MÉTODOS}

Adultos do pulgão $R$. maidis foram obtidos no CNPMS/EMBRAPA em Sete Lagoas-MG, procedendose à sua multiplicação nos Laboratórios de Biologia de Insetos do Departamento de Entomologia da Universidade Federal de Lavras - UFLA, MG. Ninfas recémnascidas provenientes dessa criação foram mantidas em câmaras climatizadas reguladas nas temperaturas de 15 , $18,21,24,27$ e $30 \pm 1^{\circ} \mathrm{C}$, UR de $70 \pm 10 \%$ e fotofase de 12 horas.

Inicialmente, uma ninfa foi colocada em placa de Petri de 9,5 x 1,5 cm, contendo uma camada de $0,5 \mathrm{~cm}$ de ágar/água a $1 \%$ e um disco de folha de milho cultivar HT 971110, de aproximadamente $5 \mathrm{~cm}$ de diâmetro. Vedou-se a parte superior da placa com filme de pvc laminado, e para evitar a condensação, fizeram-se alguns furos com alfinete entomológico. Por causa de maior facilidade no manuseio, passou-se a utilizar recipientes descartáveis de $150 \mathrm{ml}$ com tampa vazada e vedada com tecido "voil", utilizando-se secções de folha de milho e camada de ágar/água semelhantes às anteriores.

Utilizou-se o delineamento experimental inteiramente casualizado com seis tratamentos, representados pelas temperaturas com oito indivíduos para cada uma das cinco repetições, perfazendo um total de 40 ninfas/tratamento. Procedeu-se à análise de variância, e existindo diferenças significativas entre os tratamentos detectados pelo teste de médias de Scott e Knott (1974), procedeu-se à análise de regressão. Não houve necessi- 
dade de transformação, em virtude da normalidade dos dados e dos baixos coeficientes de variação.

As observações foram realizadas diariamente, durante toda a fase ninfal e adulta, avaliando-se: duração do primeiro, segundo, terceiro e quarto ínstares, fase ninfal, períodos pré-reprodutivo, reprodutivo e pós-reprodutivo, longevidade, ciclo total e capacidade diária e total de produção de ninfas. Para a determinação dos ínstares, as ninfas foram examinadas diariamente em microscópio estereoscópico, para a constatação de exúvia.

\section{RESULTADOS E DISCUSSÃO}

Fase de ninfa - As ninfas de $R$. maidis passaram por quatro ínstares, como constatado por Rezende e Cruz (1989) para essa espécie criada em laboratório e alimentada com folhas de milho e sorgo, e por Blackman (1987) e Dixon (1987), para os afídeos de um modo em geral.

Observou-se que a duração da fase de ninfa foi de 13,$3 ; 10,7 ; 6,7 ; 4,5 ; 4,7$ e 4,5 dias a $15,18,21,24$, 27 e $30^{\circ} \mathrm{C}$, respectivamente, constatando-se um decréscimo linear em todos os ínstares, em razão do aumento da temperatura na faixa de 15 a $24^{\circ} \mathrm{C}$. Contudo, acima dessa temperatura houve uma tendência de estabilização da velocidade de desenvolvimento (Tabela 1). As correlações obtidas para a duração dos ínstares em função da temperatura ajustaram-se a equações de segundo grau, observando-se a influência desse fator sobre a duração do desenvolvimento desse afídeo (Figura 1).

No terceiro ínstar houve uma redução mais evidente com o aumento da temperatura, na faixa de 15 a $30^{\circ} \mathrm{C}$, possivelmente em conseqüência de uma menor duração desse ínstar.

A duração média da fase da fase jovem de $R$. maidis foi influenciada pela temperatura, conforme constatado para cada ínstar individualmente. Com o aumento na faixa de 15 a $24^{\circ} \mathrm{C}$, houve um decréscimo de 8,8 dias, ou seja, cada acréscimo de $3^{\circ} \mathrm{C}$ causou uma redução superior a dois dias na duração do desenvolvimento (Tabela 1). Elliott e Kieckhefer (1989) observaram para $R$. padi criado em cevada, a $26^{\circ} \mathrm{C}$, uma duração de 9,1 dias para essa fase; portanto, superior a $48 \%$ ao obtido para $R$. maidis criado em milho. Essas discrepâncias possivelmente estão relacionadas à espécie de afídeo, planta hospedeira e a origem geográfica das espécies. O coeficiente de correlação $\left(\mathrm{r}^{2}\right)$ obtido foi de $98,0 \%$, ajustando-se a uma equação de segundo grau (Figura 2).

A correlação entre a temperatura e a duração dos ínstares evidenciou, de um modo geral, uma redução nas quatro condições térmicas mais baixas e um acréscimo de aproximadamente 7 horas na faixa de 24 a $30^{\circ} \mathrm{C}$, ou seja, a velocidade de desenvolvimento foi inversamente proporcional ao aumento na temperatura (Figura 3).

TABELA 1 - Duração média, em dias, $( \pm \mathrm{EP})$ da fase de ninfa de Rhopalosiphum maidis em seis temperaturas. UR de $70 \pm 10 \%$; fotofase de 12 horas. UFLA, Lavras-MG, 2001

\begin{tabular}{ccccccc}
\hline \multirow{2}{*}{ Instares } & \multicolumn{5}{c}{ Temperatura $\left({ }^{\mathbf{o}} \mathbf{C}\right)$} \\
\cline { 2 - 6 } & $\mathbf{1 5}$ & $\mathbf{1 8}$ & $\mathbf{2 1}$ & $\mathbf{2 4}$ & $\mathbf{2 7}$ & $\mathbf{3 0}$ \\
\hline $1^{\underline{\mathrm{o}}}$ & $3,4 \pm 0,1$ & $2,9 \pm 0,1$ & $2,2 \pm 0,3$ & $1,3 \pm 0,1$ & $1,4 \pm 0,1$ & $1,6 \pm 0,1$ \\
\hline $2^{\underline{\mathrm{o}}}$ & $3,5 \pm 0,2$ & $2,4 \pm 0,2$ & $1,3 \pm 0,1$ & $1,3 \pm 0,2$ & $1,4 \pm 0,1$ & $1,3 \pm 0,1$ \\
\hline $3^{\underline{o}}$ & $2,9 \pm 0,2$ & $2,5 \pm 0,2$ & $1,3 \pm 0,1$ & $1,0 \pm 0,3$ & $0,8 \pm 0,2$ & $0,6 \pm 0,1$ \\
\hline $4^{\underline{o}}$ & $3,5 \pm 0,3$ & $2,9 \pm 0,1$ & $1,9 \pm 0,2$ & $0,9 \pm 0,2$ & $1,1 \pm 0,1$ & $1,0 \pm 0,1$ \\
\hline Fase de ninfa & $13,3 \pm 1,1$ & $10,7 \pm 0,9$ & $6,7 \pm 0,4$ & $4,5 \pm 1,3$ & $4,7 \pm 1,2$ & $4,5 \pm 1,0$ \\
\hline
\end{tabular}

Ciênc. agrotec., Lavras, v. 28, n. 3, p. 520-529, maio/jun., 2004 


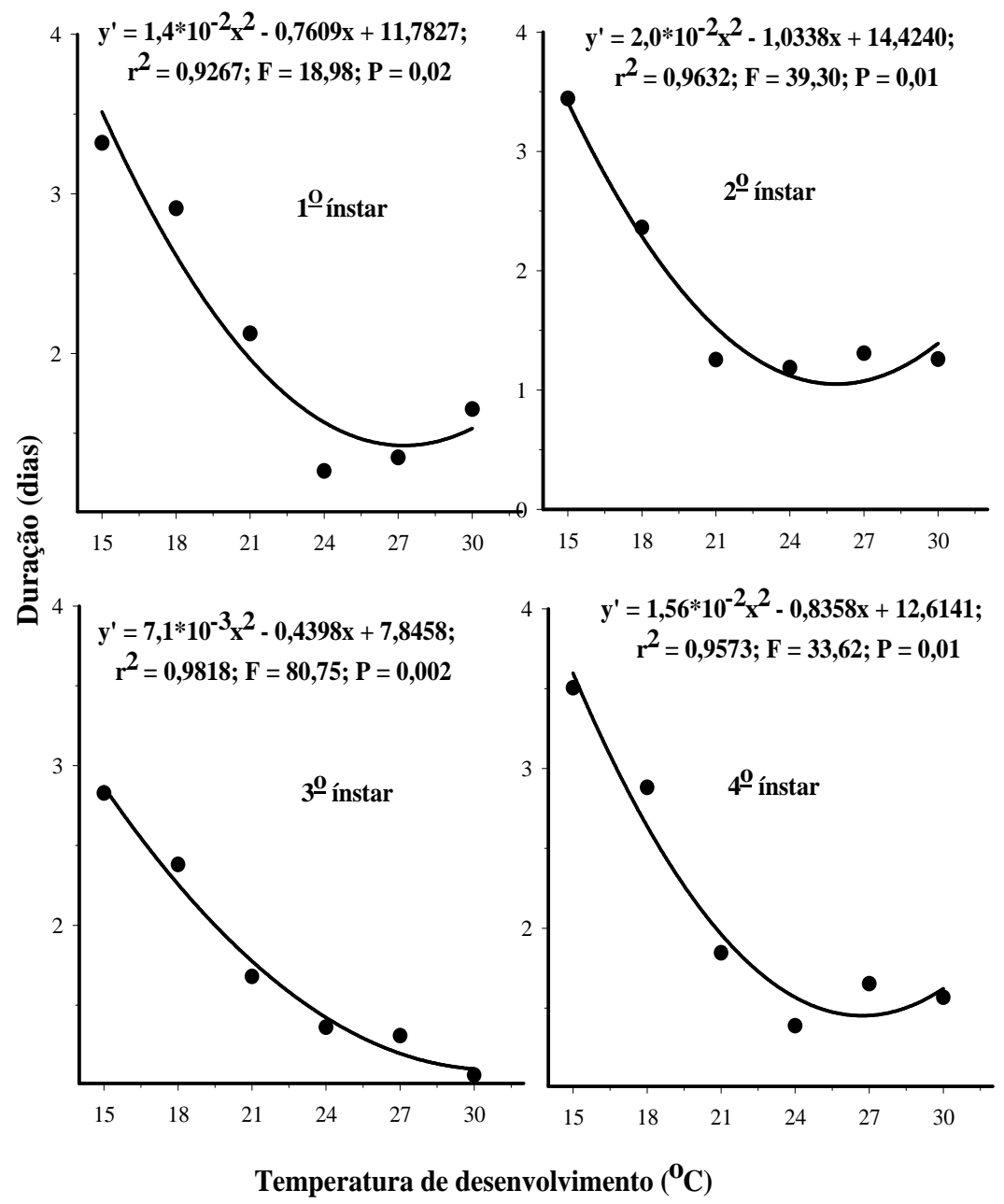

FIGURA 1 - Curvas ajustadas para a duração dos quatro ínstares de Rhopalosiphum maidis, em função da temperatura. UR de $70 \pm 10 \%$ e fotofase de 12 horas. UFLA, Lavras-MG, 2001.

Fase adulta - A duração do período préreprodutivo foi de 1,$6 ; 0,9 ; 1,2 ; 0,2 ; 0,4$ e 0,9 dias, nas temperaturas testadas, respectivamente, constatando-se uma tendência de redução desse período na faixa de 18 a $27^{\circ} \mathrm{C}$ (Figura $3 \mathrm{~A}$ ).

Em trabalhos desenvolvidos por Foott (1977) e por Belvett et al. (1965), foi demonstrado que, para $R$. maidis criado em cevada a $21^{\circ} \mathrm{C}$ e fotofase de 14 horas, a duração desse período foi de 7,0 e 8,4 dias, decrescendo para 5,9 dias a $25,5^{\circ} \mathrm{C}$, respectivamente, sendo cerca de seis, sete e vinte vezes maior ao observado neste trabalho. Evidencia-se, dessa forma, a possível influência do fator alimento na duração desse período.

$\mathrm{O}$ período reprodutivo de $R$. maidis foi de 28 dias a 15 e $18^{\circ} \mathrm{C}$, estabilizando-se entre 21 e $27^{\circ} \mathrm{C}$ com uma duração próxima a 12 dias, ao passo que a $30^{\circ} \mathrm{C}$ houve uma redução para 5 dias. Pela análise de regressão observa-se uma redução na duração dessa fase do desenvolvimento de $R$. maidis em função do aumento da temperatura (Figura 3B). Esses resultados aproximaram-se daqueles obtidos por Rezende e Cruz (1989) com insetos criados a $20^{\circ} \mathrm{C}$, os quais constataram um período de 12,3 dias.

Com relação à duração do período pósreprodutivo, constatou-se uma redução linear com o aumento da temperatura, sendo de 8,4 dias, a $15^{\circ} \mathrm{C}$, porém, com menor variação nas faixas de 18 a $21^{\circ} \mathrm{C}$ e 24 a $30^{\circ} \mathrm{C}$, com médias próximas a 6,5 e 2,5 dias, respectivamente (Figura 3C). Em experimentos conduzidos com $R$. maidis criado em cevada, Belvett et al. (1965), a 
$21^{\circ} \mathrm{C}$, e Fott (1977), a $25^{\circ} \mathrm{C}$, constataram uma duração média de 9,6 dias, sendo três dias mais longo que o verificado na faixa de 18 a $21^{\circ} \mathrm{C}$, neste trabalho. Rezende e Cruz (1989) também observaram para esse afídeo criado em sorgo, a $25^{\circ} \mathrm{C}$, uma duração de 8,4 dias. Essas discrepâncias possivelmente foram devidas à temperatura, bem como à espécie hospedeira e à origem geográfica do pulgão.

Constatou-se que a longevidade, assim como os demais parâmetros avaliados, decresceram com o aumento de temperatura, sendo aproximadamente 37 dias, na faixa de 15 a $18^{\circ} \mathrm{C}$ (Figura 4A). Foott (1977) observou para $R$. maidis criado em cevada, a $25^{\circ} \mathrm{C}$, uma longevidade de 35,8 dias. Os resultados obtidos por Rezende e Cruz (1989) para esse mesmo afídeo, a $20^{\circ} \mathrm{C}$, foram de 30,1 dias em sorgo e 24,3 dias em milho, aproximando-se dos obtidos neste trabalho, que corresponderam a 23,0 dias, a $21^{\circ} \mathrm{C}$. Com esses resultados, evidencia-se a influência direta da planta hospedeira sobre esse parâmetro biológico avaliado.

$\mathrm{O}$ ciclo biológico de $R$. maidis foi influenciado pela temperatura, obtendo-se, a $15^{\circ} \mathrm{C}$, uma duração de 52 dias, decrescendo em cerca de 6 dias com a elevação para $18^{\circ} \mathrm{C}$. A maior redução foi observada entre $18 \mathrm{e}$ $21^{\circ} \mathrm{C}$, registrando-se um decréscimo de 18 dias. Procedendo-se à análise de regressão, foi verificada maior variação na duração do ciclo, na faixa de 15 a $24^{\circ} \mathrm{C}$, a partir da qual houve uma tendência de estabilização (Figura 4B).
Chaudhary et al. (1968) observaram uma duração de 27,2 dias para o ciclo biológico de $R$. maidis em trigo, a $19^{\circ} \mathrm{C}$, constatando-se uma velocidade de desenvolvimento cerca de $40 \%$ superior àquela observada a $18^{\circ} \mathrm{C}$, neste experimento, que foi de aproximadamente 46 dias. Evidenciou-se, portanto, que, em condições semelhantes de temperatura e de criação, os fatores alimento e local de origem das espécies possivelmente influenciaram a velocidade de desenvolvimento desse afídeo.

Ao se avaliar a produção diária e total de ninfas produzidas em função da temperatura, constatou-se um acréscimo $24^{\circ} \mathrm{C}$, a partir da qual ocorreram reduções, caracterizando uma equação de segundo grau, com um coeficiente de correlação de $80 \%$ para a produção diária e $90 \%$ para a total (Figuras 5A, B). Esse fato pode ser devido a menor duração do período reprodutivo a 27 e $30^{\circ} \mathrm{C}$. Por outro lado, as temperaturas de 15 e $18^{\circ} \mathrm{C}$, embora tenham permitido um prolongamento desse período, possivelmente afetaram de forma negativa a capacidade reprodutiva desse pulgão. A maior fecundidade foi verificada a 21 e $24^{\circ} \mathrm{C}$, sendo de 4,8 e 5,9 ninfas/fêmea/dia, com um total de 65 e 69 ninfas/fêmea, respectivamente. Constata-se com esses resultados que, embora essa faixa de temperatura tenha acarretado uma redução na duração do período reprodutivo, favoreceu a produção de um maior número de ninfas em relação às demais condições térmicas estudadas.

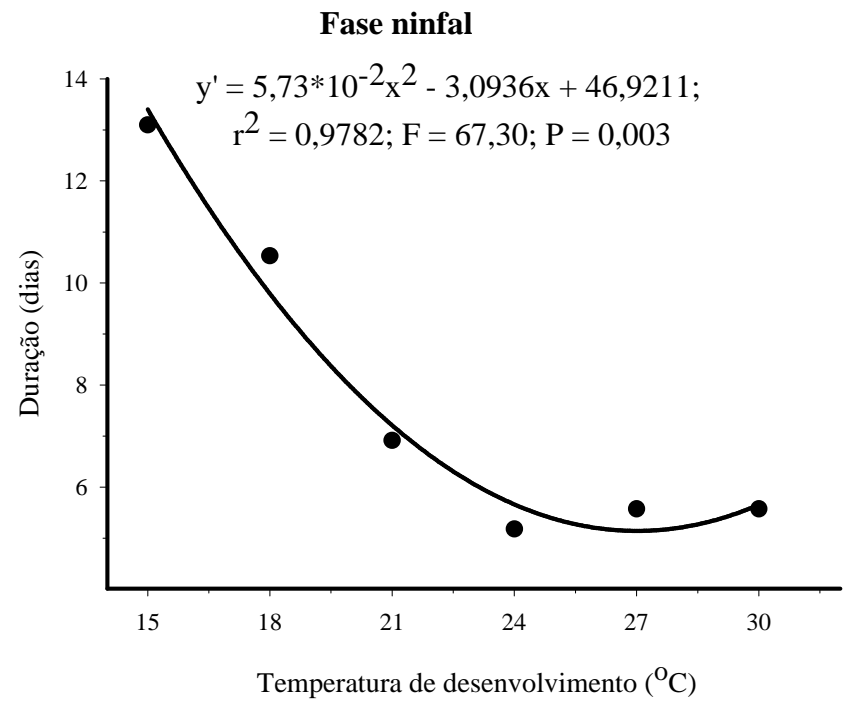

FIGURA 2 - Curvas ajustadas para a duração da fase ninfal de Rhopalosiphum maidis, em função da temperatura. UR de $70 \pm 10 \%$ e fotofase de 12 horas. UFLA, Lavras-MG, 2001. 

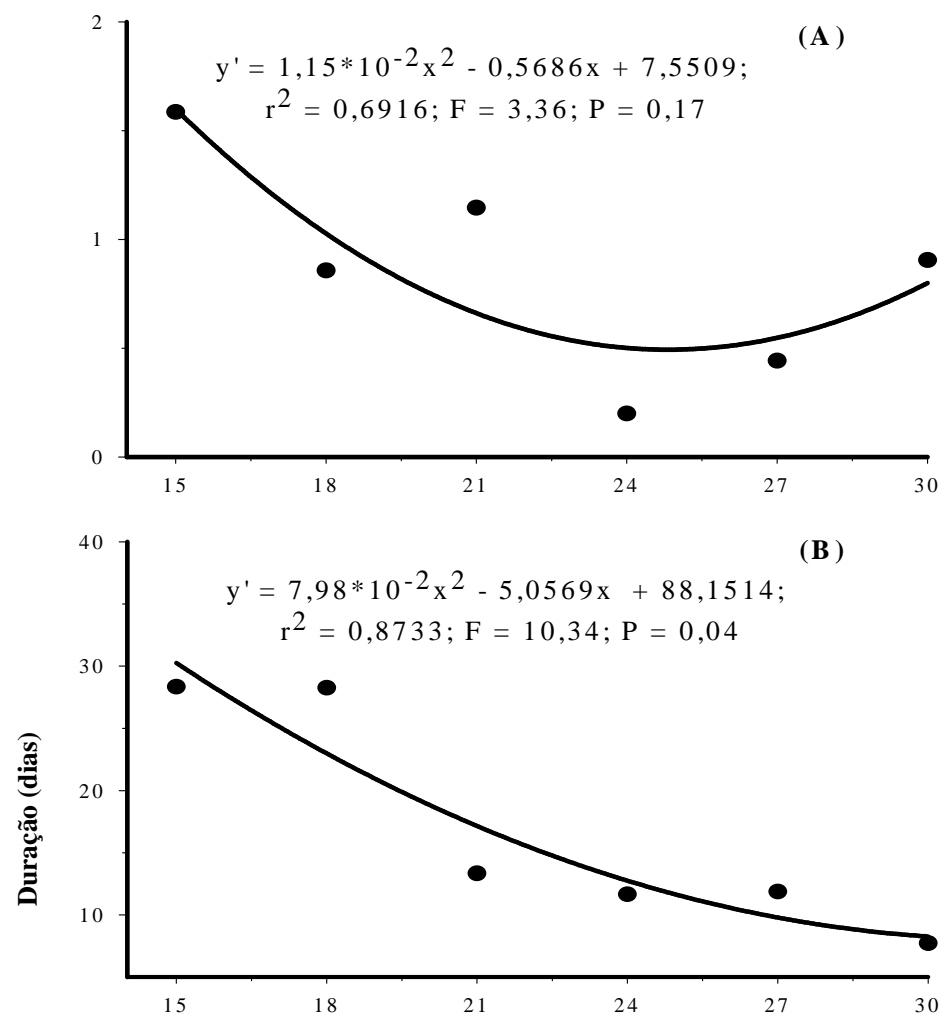

(C)

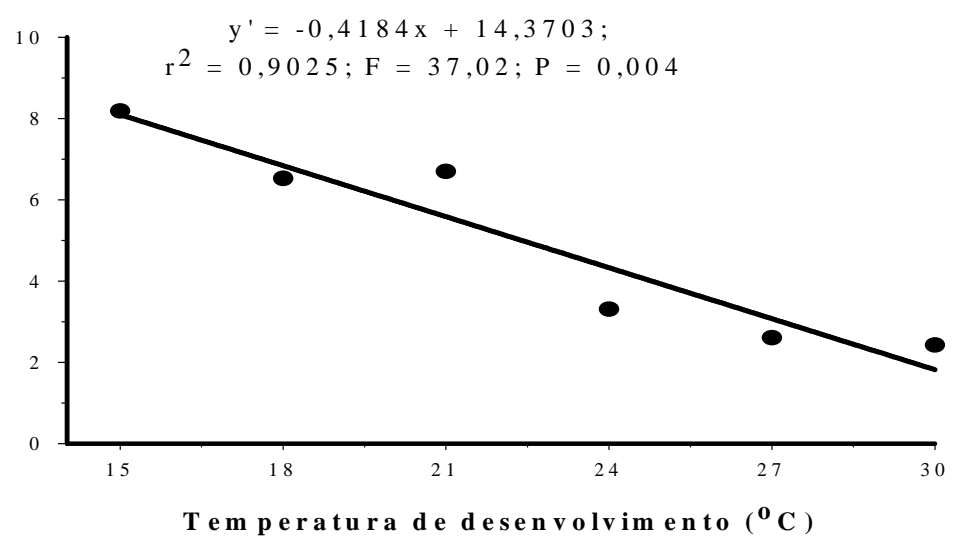

FIGURA 3 - Curvas ajustadas para: A - duração dos períodos pré-reprodutivo; B - reprodutivo e C - pósreprodutivo de Rhopalosiphum maidis, em função da temperatura. UR de $70 \pm 10 \%$ e fotofase de 12 horas. UFLA, Lavras-MG, 2001. 
(A)

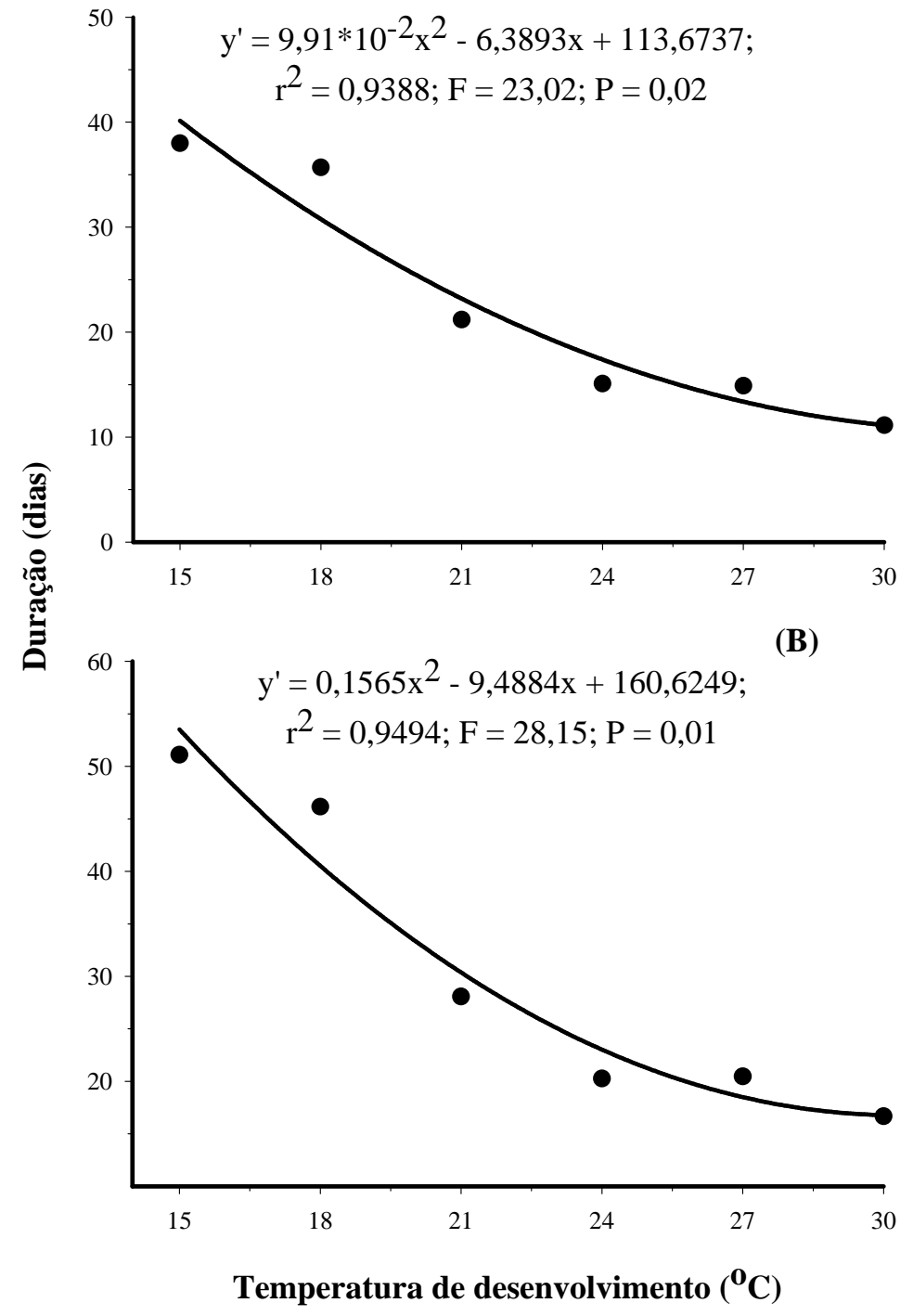

FIGURA 4 - Curvas ajustadas para: A - longevidade e B - ciclo biológico de Rhopalosiphum maidis, em função da temperatura. UR de $70 \pm 10 \%$ e fotofase de 12 horas. UFLA, Lavras-MG, 2001. 
(A)

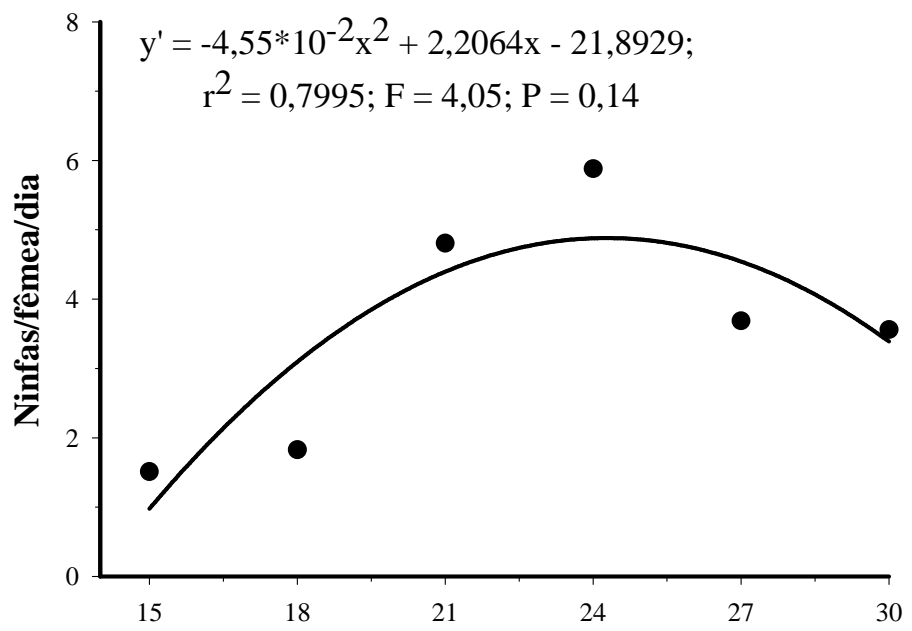

(B)

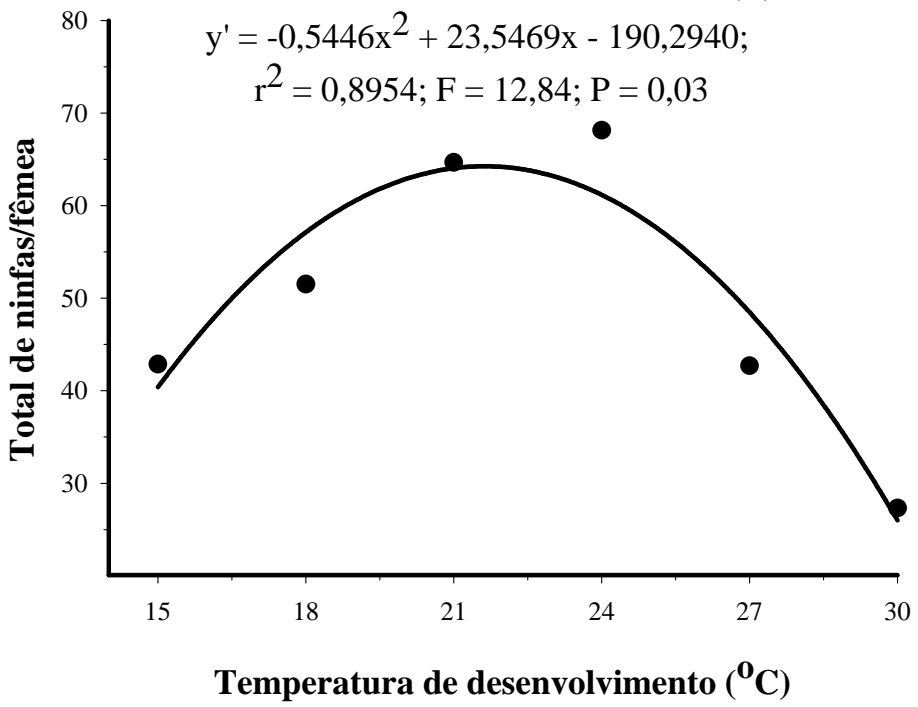

FIGURA 5 - Curvas ajustadas para: A - produção de ninfas/dia/fêmea e B - ninfas/totais/fêmea de Rhopalosiphum maidis, em função da temperatura. UR de $70 \pm 10 \%$ e fotofase de 12 horas. UFLA, Lavras-MG, 2001.

Considerando que a faixa ótima de desenvolvimento e atividade dos insetos situa-se entre 15 e $38^{\circ} \mathrm{C}$ (SILVEIRA NETO et al., 1976), e também considerando a espécie de pulgão em estudo, possivelmente a obtenção de uma menor produção total de ninfas nas faixas de 15 a 18 e 27 a $30^{\circ} \mathrm{C}$ tenha ocorrido em função de uma melhor adaptação desse afídeo em temperaturas mais amenas e, portanto, próximo aos limites estabelecidos.
Chaudhary et al. (1968) observaram uma produção média diária de 2,1 ninfas de $R$. maidis em trigo a $19^{\circ} \mathrm{C}$, assemelhando-se aos resultados obtidos neste experimento, a $18^{\circ} \mathrm{C}$, que foram de 1,9 ninfa. Essa variação na produção de ninfas quando se utilizaram plantas de trigo e milho como alimento, em temperaturas próximas, pode ser devida à adaptação desse afídeo a essas gramíneas. 
Chaudhary et al. (1968) verificaram para $R$. maidis em trigo, a $19^{\circ} \mathrm{C}$, uma produção total de 34,2 ninfas, sendo inferior em cerca de $34 \%$ do total produzido a $18^{\circ} \mathrm{C}$ neste trabalho. Foott (1977) observou uma produção total de 68,2 ninfas de $R$. maidis em milho, a $25,5^{\circ} \mathrm{C}$, assemelhando-se ao número de ninfas constatado a $24^{\circ} \mathrm{C}$ neste experimento. Assim como para a produção diária, constatou-se a influência do tipo da planta e origem geográfica das espécies, além do fator temperatura, sobre a capacidade total de produção de ninfas de $R$. maidis.

As variações entre os resultados obtidos neste trabalho e os registrados na literatura, mencionados anteriormente, podem ser atribuídas às metodologias de criação do pulgão e planta hospedeira, pois, de acordo com Parra (1999) e Chagas e Parra (2000), o uso de folhas destacadas para a criação de insetos poderá alterar a consistência dessas estruturas, quantidade de água e fluxo de nutrientes, os quais são de extrema necessidade para insetos sugadores como o pulgão $R$. maidis.

\section{CONCLUSÕES}

a) Houve influência da temperatura sobre a velocidade do desenvolvimento dos quatro ínstares, fase de ninfa, fase adulta e ciclo biológico de Rhopalosiphum maidis.

b) A capacidade reprodutiva diária e total foi afetada pela temperatura, com a faixa de 21 a $24^{\circ} \mathrm{C}$ sendo a mais favorável, evidenciando a capacidade de adaptação e desenvolvimento de Rhopalosiphum maidis.

\section{REFERÊNCIAS BIBLIOGRÁFICAS}

BELVETT, V. B.; SUN, R. Y.; ROBINSON, A. G. Observations on laboratory rearing of grain aphids (Homoptera: Aphididae). Canadian Journal of Zoology, Ottawa, v. 43, p. 619-622, 1965.

BLACKMAN, R. L. Reproduction, cytogenetics and development. In: MINKS, A. K.; HARREWINJN, P. (Eds.). World crop pests: their biology, natural enemies and control. Amsterdam: Elsevier, 1987. cap. 3, p. 163-196.

BRODBECK, B.; STRONG, D. Amino acid nutrition of herbivorous insects and stress to host plants. In: BARBOSA, P.; SCHULTZ, J. C. (Eds.). Insect outbreaks. San Diego: Academic, 1987. cap. 14, p. 347-364.
CHAGAS, M. C. M.; PARRA, J. R. P. Phyllocnistis citrella Stainton (Lepidoptera: Gracillariidae): técnica de criação e biologia em diferentes temperaturas. Anais da Sociedade Entomológica do Brasil, Jaboticabal, v. 29 , n. 2, p. 227-235, 2000.

CHAUDHARY, J. P.; RAMZAN, M.; ATWAL, A. S. Preliminary studies on the biology of wheat aphids. Indian Journal Agriculture Science, New Delhi, v. 39, n. 7, p. 672-675, 1968.

CIVIDANES, F. J. Uso de graus-dia em entomologia: com particular referência ao controle de percevejos pragas da soja. Jaboticabal: Funep, 2000. 31 p.

CRUZ, I. Inimigos naturais da lagarta-do-cartucho e pulgões na cultura do milho: Chrysoperla externa. [S.l.: s.n.], 2000a. Folder.

CRUZ, I. Milho: chegaram os sugadores. Cultivar, Pelotas, v. 2, n. 14, p. 18, 2000 b.

CRUZ, I. Pragas iniciais do milho. Cultivar, Pelotas, v. 2, n. 12 , p. $10-14,2000$ c.

DIXON, A. F. G. The way of life of aphids: host specificity, speciation and distribution. In: MINKS, A. K.; HARREWINJN, P. (Eds.). World crop pests: their biology, natural enemies and control. Amsterdam: Elsevier, 1987. cap. 4.1, p. 197-207.

DUARTE, A. P. Como fazer uma boa segunda safra. Cultivar, Pelotas, v. 3, n. 25, p. 10-18, 2001.

ELLIOTT, N. C.; KIECKHEFER, R. W. Effect the constant and fluctuating temperatures on immature development and age-specific life table of Rhopalosiphum padi L. (Homoptera: Aphididae). The Canadian Entomologist, Ottawa, v. 121, p. 131-140, 1989.

EVERLY, R. T. Loss in corn yield associated with the abundance of the corn leaf aphid, Rhopalosiphum maidis, in Indiana. Journal of Economic Entomology, College Park, v. 53, n. 5, p. 924-932, 1960.

FOOTT, W. H. Biology of the corn leaf aphid, Rhopalosiphum maidis (Homoptera: Aphididae), in Southwestern Ontario. The Canadian Entomologist, Ottawa, v. 109, p. 1129-1135, 1977. 
GASSEN, D. N. Manejo de pragas associadas à cultura do milho. Passo Fundo: Aldeia Norte, 1996. 134 p.

GASSEN, D. N.; GASSEN, F. R. Plantio direto, o caminho do futuro. Passo Fundo: Aldeia Norte, 1996. 207 p.

HŎNEK, A. Environment stress, plant quality and abundance of cereal aphids (Hom., Aphididae) on winter wheat. Journal of Applied Entomology, Hamburg, v. 112, p. 65-70, 1991.

HŎNEK, A. Host plant energy allocation to and within ears, and abundance of cereal aphids. Journal of Applied Entomology, Hamburg, v. 110, p. 68-72, 1990.

MAGAlHÃES, P. C.; DURÃES, F. O. M.; PAIVA, E. Fisiologia da planta de milho. Sete Lagoas: EMBRAPA/ CNPMS, 1995. 27 p. (Circular técnica, 20).

MARTINS, D. dos S.; FERRÃO, R. G. Ataque severo de pulgão Rhopalosiphum maidis (Fitch, 1856) na cultura de milho no norte do estado do Espírito Santo. In: COMGRESSO NACIONAL DE MILHO E SORGO, 18., 1990, Vitória, ES. Resumos... Vitória: EMCAPA, 1990. p. 61.

OS PULGÕES do milho. Revista "Correio Agropecuário”, São Paulo, ano 7, n. 4, p. 59, 1967.

PARRA, J. R. P. Técnicas de criação de insetos para programas de controle biológico. Piracicaba: ESALQ/FEALQ, 1999. 137 p.
PEÑA-MARTINEZ, M. R. Biologia de áfidos y su relación con la transmisión de virus. In: URIAS, C. M.; RODRÍGUEZ, M.; ALEJANDRE, T. A. (Eds.). Afidos como vectores de virus en México. México: Centro de Fitopatologia, 1992. v. 1, p. 11-35.

REZENDE, M. A. A.; CRUZ, I. Biologia do pulgão Rhopalosiphum maidis (Fitch, 1856) (Homoptera: Aphididae) em sorgo e milho, em diferentes temperaturas. In: CONGRESSO BRASILEIRO DE ENTOMOLOGIA, 12., 1989, Belo Horizonte. Anais... Belo Horizonte: SEB, 1989. v. 1, p. 8.

SILVEIRA NETO, S.; NAKANO, O.; BARBIN, D.; VILLA NOVA, N. A. Manual de ecologia dos insetos. São Paulo: Ceres, 1976. 422 p.

SCOTT, A. J.; KNOTT, M. A. A cluster analyses method for grouping means in the analyses of variance. Biometrics, Washington, v. 30, n. 3, p. 502-512, 1974.

WAQUIL, J. M.; OLIVEIRA, E.; PINTO, N. F. J. A.; FERNANDES, F. T.; CORREA, L. A. Efeito na produção e incidência de viroses em híbridos comerciais de milho. Fitopatologia Brasileira, Brasília, v. 21, n. 4, p. 460-63, 1996. 